\title{
Cognitive and Emotional Evaluation of an Amphibian Conservation Program for Elementary School Students
}

\section{Christoph Randler, Angelika Ilg, and Janina Kern}

ABSTRACT: The authors describe a study aimed at enhancing knowledge about amphibian species. Two classes of 3rd and 4th graders aged 9-11 years participated in the study. In addition, approximately one half of the students participated in an environmental conservation action designated to preserve migrating amphibians. During this action, students encountered living amphibians. Students who participated in the conservation action performed significantly better on achievement tests, and 4th graders performed better than 3rd graders, even when controlling for prior knowledge as a covariate, which also showed a significant influence. Pupils expressed high interest and well-being and low anger, anxiety, and boredom. Boredom and anxiety correlated negatively with residualized achievement scores. Major implications are that learning about biodiversity should (a) focus on a small number of species, (b) start in primary schools, (c) take place outdoors, and (d) be linked with classroom teaching.

KEY WORDS: amphibian identification, biodiversity, outdoor ecology teaching, tutoring, within class grouping

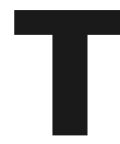

eaching biodiversity has been a challenging educational task at least since the United Nations Conference on Environment and Development, held in Rio de Janeiro, in 1992 (Gaston \& Spicer, 2004; Van Weelie \& Wals, 2002). From a didactical viewpoint, however, biodiversity is a rather ill-defined, abstract, and complex construct (van Weelie \& Wals) that has to be transformed into small entities to enhance sustained learning and understanding, especially in elementary and middle school students. The most common entity used by conservation groups is species (van Weelie \& Wals). Therefore, basic knowledge about identification and life history of ani-

Christoph Randler is a junior professor, and Angelika Ilg and Janina Kern are primary school teachers. All are at the University of Education, PH Ludwigsburg, Germany.

Copyright (C) 2005 Heldref Publications 


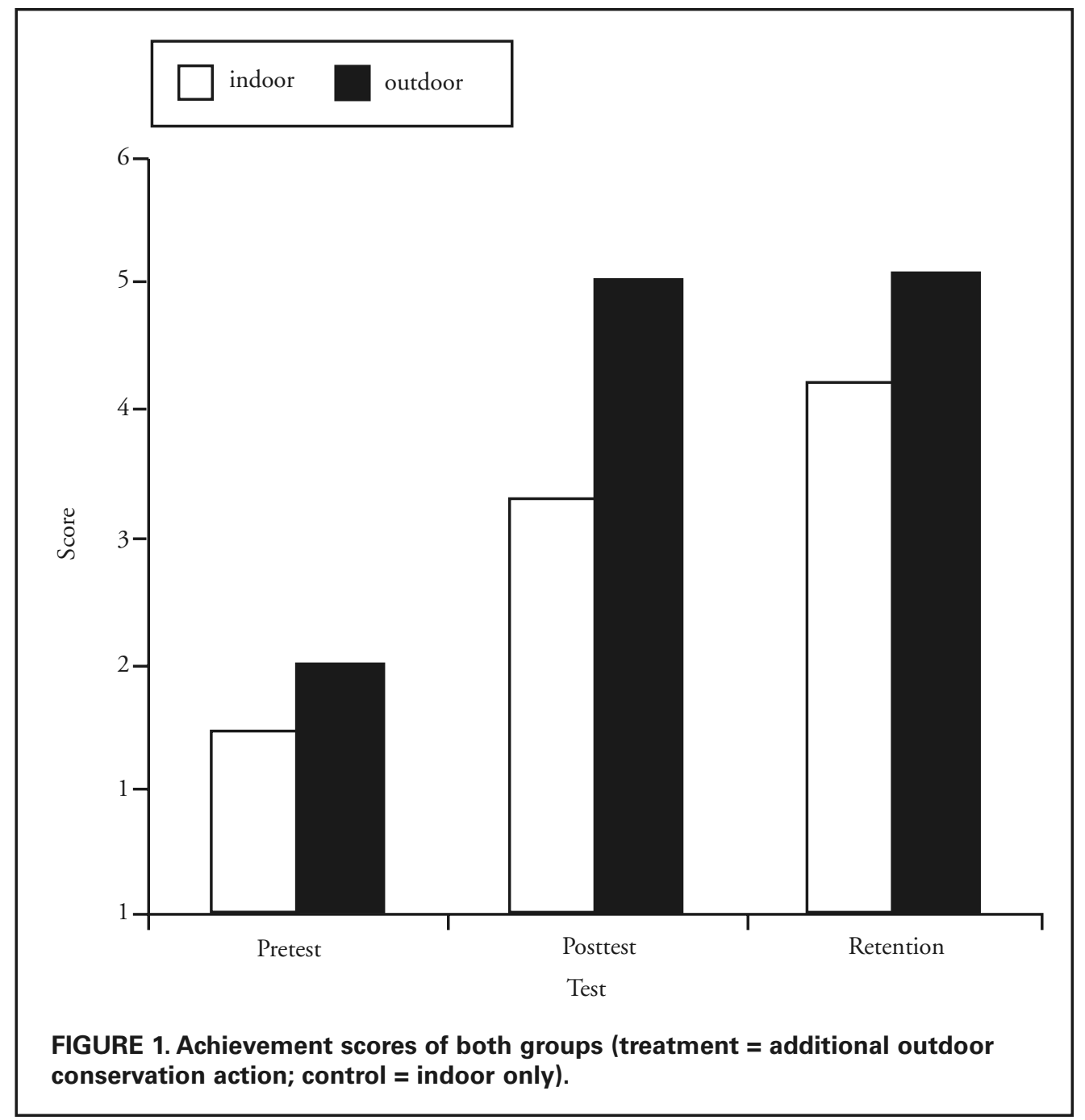

mal species has been targeted as a fundamental aspect for learning and understanding biodiversity (Gaston \& Spicer; Lindemann-Matthies, 1999; Randler \& Bogner, 2002).

When teaching biodiversity, many practitioners prefer settings with outdoor ecological education over classroom instruction (Killermann, 1998; Lock, 1998; Tilling, 2004). However, such educational lessons often deal with rather immobile taxonomic groups such as plants or invertebrates (Killermann) because amphibians, mammals, and birds sometimes are difficult to observe under natural conditions.

Within the context of ecology, many educational researchers have emphasized measuring psychological constructs, such as attitude, perception, and other personality factors, rather than knowledge (for an overview, see Bogner, 2002; Randler \& Bogner, 2002). Therefore, monitoring learning outcome is a useful task to support the possible impact of outdoor ecology education. Nevertheless, studies about the effectiveness of teaching and learning about amphibians in an outdoor setting are scarce. 
Furthermore, most studies concerning environmental actions and outdoor ecology instruction predominantly have focused on middle school students, adolescents, and university students rather than on elementary students (e.g., Bogner, 1999, 2002; Bowler, Kaiser, \& Harting, 1999). Nevertheless, some researchers have suggested that such educational approaches should start in elementary school. For example, Kellert (1985) identified important changes in the development of children's perceptions of animals and found three stages. The first transition, (6-9 years of age) involved changes in affective and emotional variables; the second transition from 10 to 13 years of age was marked by a major increase in cognitive abilities. The third stage (13 to 16) witnessed a dramatic broadening of ethical concerns and ecological applications. Therefore, intervention studies focusing on the first transition stage seem promising, especially when knowledge and emotional factors are linked and when the cognitive content is not overemphasized.

Furthermore, we believe that outdoor education could be enhanced and should be supported by previous learning within the classroom to prepare students for forthcoming issues and tasks in nature and to prevent students from a cognitive load and novelty effects (Falk, 1983; Falk, Martin, \& Balling, 1978; Sweller, van-Merrienboer, \& Paas, 1998). Such a cognitive load (or novelty) may arise when students are confronted simultaneously with different environmental conditions. In terms of amphibian conservation actions, this might mean (a) species that are new to students, (b) different settings compared with the familiar classroom setting (weather conditions, nighttime), and (c) different learning environments, such as working in groups and doing hands-on activities or encountering living animals. Therefore, students who are not prepared by any prior teaching in a familiar setting, such as the classroom, might benefit less from outdoor education (see Falk).

In addition, original objects are regarded as a primary and motivating source of learning (Killermann, 1996, 1998). Animals rank high as a favorite interest of children (Morgan, 1992). However, the assumption that living animals elicit positive reactions and emotions and, therefore, higher learning success remains poorly empirically tested (Morgan). Morgan found that a balance between cognitive input and level of involvement fosters learning success. Therefore, the combination of classroom activities prior to a field trip to enhance knowledge and of an outdoor activity to foster emotions seems a worthwhile task.

Another problem with many studies lies in the design of educational experiments. Some investigators compared groups that received a thoroughly developed treatment with a control group that did not receive any training in species identification or in $\mathrm{EE}$ (see, for example, discussion in Leeming, Porter, Dwyer, Cobern, and Oliver, 1997; Bogner, 1999). It is not surprising that most control groups performed significantly worse-a fact discussed by Leeming et al. In the present study, we aimed for an educational setting that compared both indoor and outdoor education and that incorporated the control group within the two classes under survey. Such a quasiexperimental approach could be considered ecologically valid in terms of experimental design (Keeves, 1998).

\section{Method}

\section{Educational Program}

Schooling took place in the federal state of Baden-Württemberg, Germany. During the conservation action, students usually encountered five amphibian species in considerable numbers: common toad (Bufo bufo), smooth newt (Triturus vulgaris), alpine newt (Triturus alpestris), common frog (Rana temporaria), and spring (agile) frog (Rana dalamtina). 
The program was divided into two parts and was embedded into teaching activities prior to and after the conservation action. All students in one third-grade class and one fourth-grade class $(N=$ 46) participated in the indoor program, whereas the additional outdoor program was attended by 26 students from both classes.

\section{Indoor Classroom Program}

The unit started with a motivating part (radio play) about the one amphibian species and its life history. Afterward, students worked together in groups of three or four members, as this is considered an optimal group size (Lou et al., 1996). The students received a small booklet guiding them through the learning activity, which was self-regulated. Different tasks were assembled in the classroom, and the pupils moved from one desk to another to complete the booklet. Some parts of the unit dealt with identification, and an identification book and plastic models of the five species were present during the classroom activity. These models were obtained from a commercial scientific producer (Schlüter-Biologie, Winnenden, SW Germany) and closely resembled original animals. Apart from identification, information about amphibian development, habitat requirements, predation, and conservation also provided contextual knowledge (see discussion in Randler \& Bogner, 2002). After the additional outdoor program, students received information about ecology, migration, and the winter rigidity of amphibians. Students who had participated in the conservation action related their experience to the other students (i.e., peer tutoring in Neber, 1995).

\section{Additional Outdoor Program}

The additional outdoor program took place in the final 2 weeks of March 2005 during peak toad and newt migration, which coincided with the school's Easter holiday break. To minimize novelty effects of the environment (Falk, 1983), a conservation action was visited located in the students' residential town. Twenty-six students participated voluntarily in the outdoor work. During this action, students were guided by students from the University of Education in Ludwigsburg and collected, identified, and counted all amphibians on their annual way to the breeding pond. These animals are endangered especially by traffic and to a lesser extent by habitat destruction. An additional teaching sequence did not happen, but the students were encouraged to collect and identify the animals themselves under the guidance of the university students.

\section{Design and Testing Procedure}

The testing design is shown in Figure 1. In total, 46 students ( 23 boys, 23 girls) participated in the study (23 third graders and 23 fourth graders; aged 9-11 years). Both classes were taught prior to and after the outdoor conservation unit by two preservice students of the University of Education (Angelika Ilg and Janina Kern). Students from both classes who were available during the Easter holiday break participated in the outdoor conservation unit and were instructed by the same two preservice teachers. Because a teacher can have a significant effect on learning and retention (GläserZikuda, Fuß, Laukenmann, Metz, \& Randler, 2005), it is important to control for this variable (see also Randler \& Bogner, 2004). Therefore, teacher effects were negligible in our treatment-control design.

Students absent during the holidays served as the control group. We considered this selection procedure as much better compared with random selection by random tables or a computer program, because students who would have been selected to stay absent from the conservation action might become frustrated (see also Bogner, 1999). A sample of 26 students took part in the conservation action. Furthermore, students were offered five different evening visits to the conservation action: 23 
students visited the conservation action one time, 2 students visited two times, and 1 student visited three times. Therefore, a dichotomous variable for each student was created $(1=$ participant, $0=$ nonparticipant). There was no difference between boys $(n=14)$ and girls $(n=12)$ in visiting the conservation action (binomial test: $p=.845, n s$ ). Distribution of the students who participated did not differ between both classes, $\chi^{2}(1, N=26)=0.354, p=.552$.

To test prior knowledge and for all subsequent tests, we used a simple sheet of paper where six species were depicted in color (Rana temporaria, Bufo bufo, Triturus alpestris, Triturus vulgaris, Salamandra salamandra, and Pelobates fuscus). P. fuscus was not encountered during classroom teaching or the outdoor activity but served as an internal control to test whether significant improvement of the concept took place. A further question dealt with the position of the male using a picture of paired common toads in their typical mating position. Students had to determine which toad was the male. We used a color laser printer to print out all tests in full color. The students labeled the species as precisely as possible. Each correct species identification received the value 1 . When students were able to identify only the correct genus, they received 0.5 point because we wanted to improve the knowledge in general. For example, many students were not able to even identify a frog correctly or left the sheet partially blank prior to teaching, but afterward they were able to identify at least the genus. This was regarded as an improvement of identification knowledge. As both Rana species are extremely difficult to distinguish (especially for elementary school students), we accepted both answers as correct.

Students were tested prior to the educational treatment (pretest, T-1), 1 week after the program to assess short-term effects at the beginning of the very first lesson (posttest, T-2), and with a delay of 4-5 weeks to assess retention effects (T-3). None of these tests were used for grading to remove extrinsic motivation as a confounding variable that might significantly influence the outcome of our study. Retention tests usually are applied with such a delay to ensure that the knowledge has settled (Bogner, 1999). Students were unaware of any further testing.

In addition, we measured emotional variables (i.e., interest, well-being, anxiety, anger, boredom) using an instrument developed by a team of researchers at the University of Education in Ludwigsburg (Gläser-Zikuda et al., 2005; Laukenmann et al., 2003). This instrument measures the students' subjective assessment at the end of a lesson or educational unit, using a 5-point Likert scale ranging from $1=$ very uninteresting to $5=$ very interesting. Every psychological construct is measured by different items (see Gläser-Zikuda et al. for the psychometric measurements). For example, for the interest construct, students responded to the statement "The educational unit was interesting for me": for well-being, "I enjoyed the unit"; for anxiety, "I felt insecure during the unit"; for boredom, "I felt bored"; and for anger, "Some things made me angry." Furthermore, we asked the students to grade the unit $(1=$ best, $6=$ worst $)$.

Our study provides a high ecological validity in terms of experimental design (Keeves, 1998) because all students came from the same hometown, attended the same school environment, had the same novelty or unfamiliarity with the conservation site, and were taught by the same two teachers in class and during the conservation action.

\section{Statistics}

As achievement data were normally distributed, we used a general linear model using Type III sum of squares for unbalanced data. Emotional variables were highly skewed either to the lower or upper end of the 5-point Likert scale (ceiling and bottom effects). Therefore, we used nonparametric tests when these variables were calculated. All tests were carried out two-tailed using SPSS 13.0. (SPSS, German version, Munich). The results presented here are means \pm standard errors $(S E)$. As prior 
knowledge influences achievement significantly, we regressed prior knowledge against the posttest and used these residuals when correlating with emotional variables.

\section{Results}

As expected, prior knowledge showed a significant influence on the posttest $(r=.374, p=.010$, $N=46$ ). The additional outdoor group did not significantly differ from the indoor group prior to teaching: T-1, $t(44)=-1.608, p=.11$; after the intervention, the treatment group differed significantly from the control group, T-2, $t(44)=-4.021, p<.001$ (Figure 1). Significant differences remained between the two groups on the retention test: T-3, $t(43)=-1.947, p=.05$ (Figure 2). Nevertheless, students from both groups significantly improved their knowledge from T-1 to T-2: treatment, $t(25)=10.497, p<.001$; control, $t(19)=5.203, p<.001$; and from T-1 to T-3: treatment, $t(25)=9.803, p<.001$; control, $t(18)=7.074, p<.001$ (Figure 2 ).

We found marginally significant differences between boys and girls prior to the educational treatment (T-1): boys, $2.0 \pm 0.26$; girls, $1.4 \pm 0.17 ; t(44)=2.099, p=.042$. However, these differences merged after the unit (T-2): boys, $4.6 \pm 0.28$; girls, $3.8 \pm 0.38 ; t(44)=1.578, p=.122$; and $4-5$ weeks later (T-3): boys, $4.9 \pm 0.29$; girls, $4.5 \pm 0.35 ; t(43)=0.937, p=.354$. To account for possible confounding variables, we applied a multivariate general linear model using posttest and retention test as dependent variables; gender, treatment, and grade as independent variables; and pretest as the covariate. In the initial model, all two-way interactions and the three-way inter-

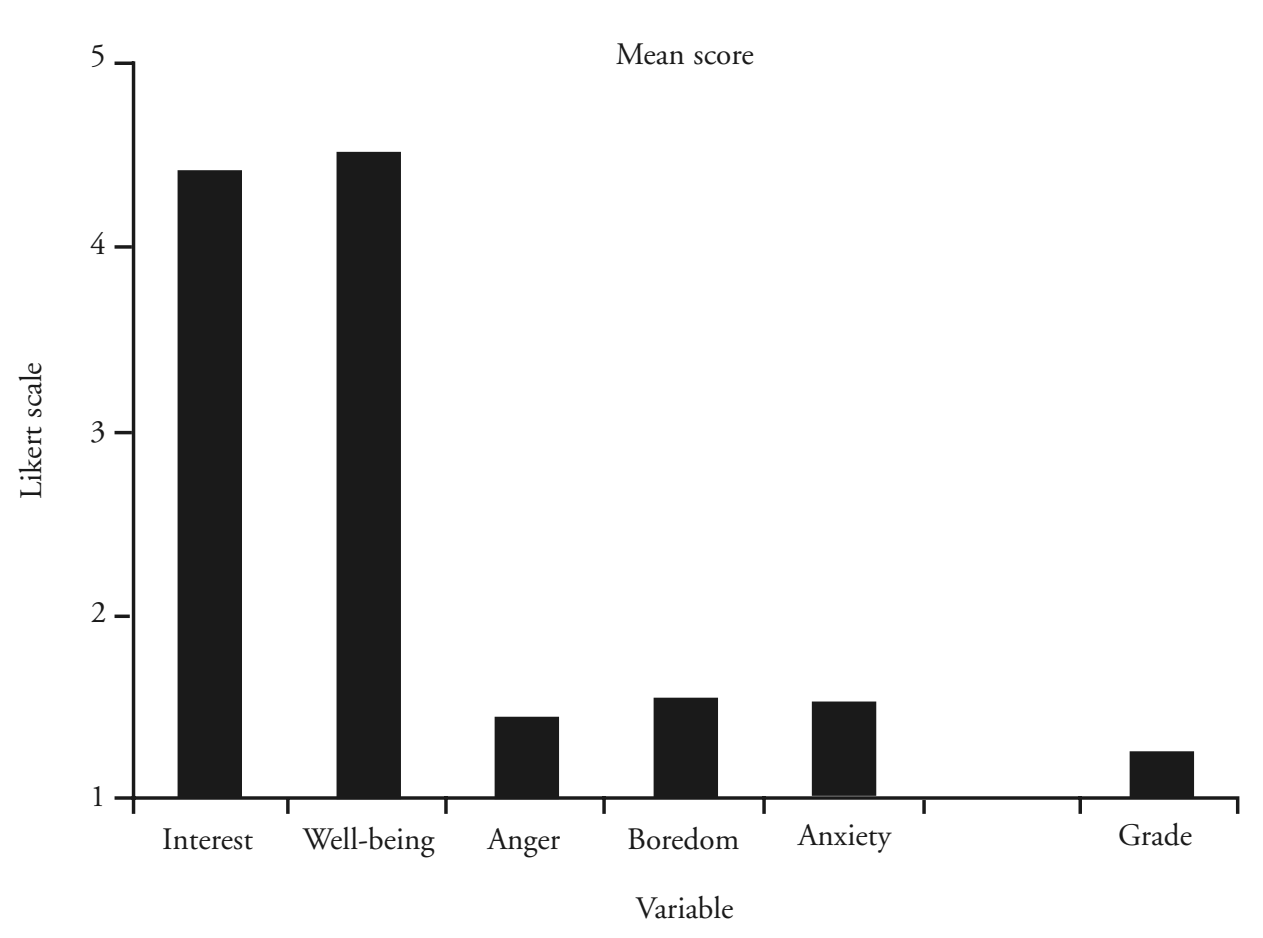

FIGURE 2. Mean Scores of emotional variables (data from both groups pooled). 
action were insignificant $(p>.05)$, and were subsequently removed. The second model found no influence of gender $(p=.622)$. Therefore, the final model comprised the variables treatment, grade, and pretest as covariates (Table 1). Total explained variances (effect sizes) were high (partial $\eta^{2}$ : posttest, .349; retention, .289; based on the final model). Treatment students and fourth graders performed significantly better.

We found no differences between the two groups (indoor vs. outdoor) concerning emotional variables (Table 2); therefore, data from both groups were pooled (Figure 2). In addition, no differences between boys and girls existed. Students expressed extremely high interest and high well-being during the educational unit, whereas boredom, anger, and anxiety were fairly low.

The residuals from the regression of prior knowledge against the posttest, $F(1,44)=7.173$, corrected $\mathrm{R}^{2}=.121, p=.010$, correlated significantly with two of the five variables: boredom $(r s=-.303$, $p=.041)$ and anxiety $(r s=-.308, p=.037)$, whereas no correlations existed between knowledge residuals and anger $(p=.512)$, interest $(p=.906)$, or well-being $(p=.242)$. Most pupils gave the units good grades (Table 1).

\section{Discussion}

Prior knowledge has shown an influence on subsequent learning. Often, prior knowledge explains most of the variance in subsequent tests (Einsiedler \& Treinies, 1997; Schiefele \& Rheinberg, 1997). We controlled for this by linear models and residual techniques. The treatment group scored significantly higher on both the posttest and retention test. This is interesting because other studies have failed to show such marked and significant differences regarding cognitive abilities between treatments, especially when different treatments were compared (e.g., Armstrong \& Impara, 1991; Bowler et al., 1999). Effect sizes were high concerning treatment and grade, both of which had a higher explained variance compared with prior knowledge. This might be a result of low prior knowledge, especially in amphibian identification.

Interestingly, pupils from the control group showed a significant positive shift in their knowledge from posttest to retention test while the scores of the treatment group remained similar. The posttest was applied before any further teaching took place. We suppose that the clearly visible learning effect from posttest to retention in the control group is a result of the following lessons in which the treatment students were encouraged to report their experience gathered during the conservation actions to their classmates. This provides some kind of peer tutoring, which has been found to have a sig-

TABLE 1. Multivariate General Linear Model Analysis Results

\begin{tabular}{lcccc}
\hline \hline Effect & Wilks's $\Lambda$ & $F(4,45)$ & $p$ & Partial $\eta^{2}$ \\
\hline Constant & & & & \\
Treatment (outdoor vs. indoor only) & .746 & 61.099 & $<.001$ & .753 \\
Grade & .747 & 6.977 & .003 & .258 \\
Pretest & .883 & 6.773 & .003 & .252 \\
& & 2.646 & .083 & .116 \\
\hline
\end{tabular}

Note. Posttest and retention test were the dependent variables, prior knowledge (pretest) was covariate, and gender, grade, and treatment were fixed factors (initial model). Final model after removing all nonsignificant factors and interactions $(p>.1)$. 


\section{TABLE 2. Means and Standard Errors of Students' Responses to Emotional Variable Questions and Class Grade, by Treatment Group}

\begin{tabular}{llll}
\hline \hline Variable & $n$ & $M$ & $S E$ \\
\hline $\begin{array}{lll}\text { Interest } \\
\quad \text { Control }\end{array}$ & 20 & 4.42 & \\
$\quad$ Treatment & 26 & 4.40 & 0.12 \\
$\begin{array}{l}\text { Well-being } \\
\quad \text { Control }\end{array}$ & 20 & 4.54 & \\
$\quad$ Treatment & 26 & 4.47 & 0.10 \\
Anger & & & 0.14 \\
$\quad$ Control & 20 & 1.55 & 0.16 \\
$\quad$ Treatment & 26 & 1.34 & 0.09 \\
Boredom & & & \\
$\quad$ Control & 20 & 1.50 & 0.17 \\
$\quad$ Treatment & 26 & 1.56 & 0.17 \\
Anxiety & & & \\
$\quad$ Control & 20 & 1.47 & 0.16 \\
$\quad$ Treatment & 26 & 1.53 & 0.23 \\
Grade & & & \\
$\quad$ Control & 20 & 1.25 & 0.06 \\
$\quad$ Treatment & 25 & 1.23 & 0.05 \\
& & &
\end{tabular}

Note. Treatment $=$ additional outdoor activity. Students rated the emotional variables on a 5 -point scale $(1=$ very uninteresting, $5=$ very interesting $)$ and graded the class on a 6 -point scale $(1=$ best, $6=$ worst $)$.

nificant positive effect on learning and retention (Neber, 1995). These results are encouraging because they show that students who do not participate in a specific (outdoor) activity might still benefit when participating individuals are encouraged to report their experiences, ideally in small groups of three to four members (Lou et al., 1996). This could be organized in a rotating system where student groups move from one tutor to another.

Another major conclusion is that outdoor ecological activities should take place during the regular school year and students should visit habitats in their vicinity regularly to reduce novelty. Although many studies have shown a highly significant improvement in either cognitive learning or in environmental perception (with a focus on enhancing preservation attitudes), one should keep in mind that residential outdoor programs are expensive and often linked with traveling, which might lead to lower acceptance of such programs. Schools should provide their students with local outdoor ecological programs.

Regarding the emotional variables, we found no superiority of the additional outdoor activity. This was an unexpected result. However, the ratings of the students showed rather skewed ceiling and bottom effects (in terms of Likert scale ratings), which might have influenced the outcome. Students who were absent from the conservation activity already rated interest and well-being so high that these measurements could not be increased in statistical terms. Animals per se might be such an interesting topic that was assessed as highly interesting already in the indoor setting. Interest in ani- 
mals is usually highest in primary school students and decreases significantly after the 5th and 6th years of schooling when more interest is expressed in human biology (Löwe, 1987).

Another unexpected result was the low level of anxiety. One would expect a higher level of anxiety, especially when encountered with animals like amphibians (which some persons may label as "ugly"). This clearly supports the use of such animals in either the classroom or outdoors (see Morgan, 1992). With regard to the correlations between achievement and emotional variables, we found weak negative correlations between achievement and either boredom or anxiety. Students who experienced the program as boring or showed a higher anxiety scored significantly lower on the posttest and retention test. This is in line with previous results in biology education (Randler \& Bogner, 2004). Unexpectedly, there was no correlation between interest and well-being and achievement. Such correlations have been found in physics education and in eighth and ninth graders during an ecological curriculum using a similar instrument for measuring emotions (Gläser-Zikuda et al., 2005; Laukenmann et al., 2003; Randler \& Bogner). This might again result from ceiling effects and a low variance in the emotional variables. However, the correlation between interest and achievement becomes stronger as students mature (Schiefele \& Csikszentmihalyi, 1998; Schiefele \& Rheinberg, 1997). Therefore, the young age of the pupils might explain the missing correlation.

Another general aspect lies in the age of the students. Such educational approaches should start in elementary schools. Kellert (1985) identified a transition stage from 6 to 9 years of age that predominantly involved changes in affective and emotional variables, but not in cognitive abilities. This is in line with our emotional results found in this study. Therefore, intervention studies focusing on this first transition phase seem promising because interest is high during this specific phase. In turn, the cognitive aspects (e.g., number of species) should be reduced, as in this present study, to ensure better retention in this stage of development (Kellert; Randler \& Bogner, 2004). Furthermore, these cognitive aspects were linked with emotional ones when students encountered living animals during the conservation action. This might support the learning effects.

Furthermore, students should be prepared for outdoor activities by a preceding educational unit in the classroom. Some studies have found that modern teaching approaches (e.g., outdoor ecology) scored significantly worse or did not reach any significant effect when compared with a rather traditionally taught control group (e.g., Killermann, 1996; Randler \& Bogner, 2004). This has been found in different educational activities such as experiments, modern media, or different teaching strategies (learner centered vs. teacher centered). Falk (1983) suggested that children's perception of the novelty of the environmental setting affects their learning outcome. Great novelty can inhibit learning; therefore, outdoor experience in elementary school students should make use of familiar settings in the students' residential town if cognitive aspects are in the main focus.

\section{ACKNOWLEDGMENT}

This study was partly funded by the University of Education, PH Ludwigsburg by Grant 14305771 "Biodiversität lehren und lernen" from the Bundesministerium für Bildung und Forschung Germany (JP C.R.) and supported by the town of Ludwigsburg. The lessons were carried out by A. Ilg and J. Kern. We especially thank G. Topaltzis for inputting the data.

\section{REFERENCES}

Armstrong, J. B., \& Impara, J. C. (1991). The impact of an environmental education program on knowledge and attitude. The Journal of Environmental Education, 22, 36-40.

Bogner, F. X. (1999). Empirical evaluation of an educational conservation programme introduced in Swiss secondary schools. International Journal of Science Education, 21, 1169-1185.

Bogner, F. X. (2002). The influence of a residential outdoor education programme to pupil's environmental perception. European Journal of Psychology of Education, 18, 19-34.

Bowler, P. A., Kaiser, F. G., \& Harting, T. (1999). A role for ecological restoration work in university environmental edu- 
cation. The Journal of Environmental Education, 30, 19-26.

Einsiedler, W., \& Treinies, G. (1997). Effects of teaching methods, class effects, and patterns of cognitive teacher-pupil interactions in an experimental study in primary school classes. School Effectiveness and School Improvement, 8, 327-353.

Falk, J. H. (1983). Field trips: A look at environmental effects on learning. Journal of Biological Education, 17, $137-142$.

Falk, J. H., Martin, W. W., \& Balling, J. D. (1978). The novel field trip phenomenon: Adjustment to novel settings interferes with task learning. Journal of Research in Science Education, 15, 127-134.

Gaston, K. J., \& Spicer, J. I. (2004). Biodiversity. Oxford: Blackwell Oxford.

Gläser-Zikuda, M., Fuß, S., Laukenmann, M., Metz, K., \& Randler, C. (2005). Promoting students' emotions and achievement-Instructional design and evaluation of the ECOLE approach. Learning \& Instruction, 15, 481-495.

Keeves, J. P. (1998). Methods and processes in research in science education. In B. J. Fraser \& K. G. Tobin (Eds.), International handbook of science education. Part 2 (pp. 1127-1153). Dordrecht, The Netherlands: Kluwer.

Kellert, S. R. (1985). Attitudes towards animals: Age-related development among children. The Journal of Environmental Education, 16, 29-39.

Killermann, W. (1996). Biology education in Germany: Research into the effectiveness of different teaching methods. International Journal of Science Education 18, 333-346.

Killermann, W. (1998). Research into biology teaching methods. Journal of Biological Education, 33, 4-9.

Laukenmann, M., Bleicher, M., Fuß, S., Gläser-Zikuda, M., Mayring, P., \& von Rhöneck, C. (2003). An investigation of the influence of emotional factors on learning in physics instruction. International Journal of Science Education, 25, 489-507.

Leeming, C. L., Porter, B. E., Dwyer, W. O., Cobern, M. K., \& Oliver, D. P. (1997). Effects of participation in class activities on children's environmental attitudes and knowledge. The Journal of Environmental Education, 28, 33-42.

Lindemann-Matthies, P. (1999). Children's perception of biodiversity in everyday life and their preferences for species. Unpublished doctoral dissertation, University of Zürich, Switzerland.

Lock, R. (1998). Fieldwork in the life sciences. International Journal of Science Education, 20, 633-642.

Lou, V., Abrami, P. C., Spence, J. C., Poulsen, C., Chambers, B., \& d'Apollonia, S. (1996). Within-class grouping: A metaanalysis. Review of Educational Research, 66, 423-458.

Löwe, B. (1987). Interessenverfall im Biologieunterricht [Decrease of interest in biology]. Unterricht Biologie, 11(124), $62-65$.

Morgan, J. M. (1992). A theoretical basis for evaluating wildlife-related education programs. The American Biology Teacher, 54, 153-157.

Neber, H. (1995). Explanations in problem-oriented, cooperative learning. In R. Olechowski \& G. Khan-Svik (Eds.), Experimental research on teaching and learning (pp. 158-166). Frankfurt, Germany: Lang.

Randler, C., \& Bogner, F. (2002). Comparing methods of instruction using bird species identification skills as indicators. Journal of Biological Education, 36, 181-188.

Randler, C., \& Bogner, F. (2004). Emotional and cognitive aspects of learning: The ecological unit "Lake.” In I. Eilks \& B. Ralle (Eds.), Quality in practice-oriented research in science education (pp. 117-124). Aachen, Germany: Shaker.

Schiefele, U., \& Csikszentmihalyi, M. (1998). Interest and the quality of experience in classrooms. Studies in Educational Psychology, 6, 1-23.

Schiefele, U., \& Rheinberg, F. (1997). Motivation and knowledge acquisition: Searching for mediating processes. Advances in Motivation and Achievement, 10, 251-301.

Sweller, J., van Merrienboer, J. J. G., \& Paas, F. G. W. C. (1998). Cognitive architecture and instructional design. Educational Psychology Review, 10, 251-296.

Tilling, S. (2004). Fieldwork in UK secondary schools: Influences and provision. Journal of Biological Education, 38, 54-58.

Van Weelie, D., \& Wals, A. (2002). Making biodiversity meaningful through environmental education. International Journal of Science Education, 24, 1143-1156. 
Copyright of Journal of Environmental Education is the property of Heldref Publications. The copyright in an individual article may be maintained by the author in certain cases. Content may not be copied or emailed to multiple sites or posted to a listserv without the copyright holder's express written permission. However, users may print, download, or email articles for individual use. 